\title{
Câncer de mama: efeito prognóstico da resposta patológica completa após quimioterapia neoadjuvante
}

\author{
Acadêmicos: Victor Van Vaisberg, Mariana da Silva Vilas Boas, Bruno de Oliveira Stephan \\ Orientadores: Adriana Reis Brandão Matutino, Julianne Maria da Silva Lima, Max Senna Mano
}

Introdução: O tratamento do câncer de mama em estágio localmente avançado é multimodal e tem intenção curativa. A quimioterapia neoadjuvante (QT-NEO) promove maior taxa de cirurgias conservadoras e melhor avaliação da resposta tumoral à terapia sistêmica, sendo a resposta patológica completa (RPC) definida mais consensualmente como ausência de doença residual (ypT0 ypN0) no estadiamento cirúrgico. A associação da RPC com um prognóstico favorável torna esse desfecho atrativo aos estudos de esquemas neoadjuvantes e por isso a análise desse desfecho faz-se impactante.

Objetivos: O objetivo desse estudo é de descrever as características clínicas terapêuticas de mulheres com câncer de mama localmente avançado submetidas à QT-NEO e que obtiveram RPC em um centro oncológico no período de 2008-2014, comparando-as com dados da literatura.

Metodologia: Pacientes com câncer de mama localmente avançado submetidas a QT-NEO que obtiveram RPC foram selecionadas para análise. Foram avaliadas características tumorais, estadiamento clínico inicial, características do tratamento, toxicidades, resposta patológica ao tratamento neoadjuvante, tratamentos adjuvantes, recidiva de doença e óbitos.

Resultados: No total, 120 pacientes apresentaram RPC, com idade mediana de 49,69 anos. Mais de 95\% eram do tipo carcinoma ductal invasivo, sendo que a maioria (60\% e 36\%) apresentavam grau histológico 2 e 3, respectivamente. Aproximadamente 52\% eram isoladamente Her-2 positivo, 10\% eram hormônio-sensíveis e 35\% eram triplo-negativo. O Ki-67 mediano foi de 48\%. O protocolo de quimioterapia AC-T foi aplicado em 49,1\% das pacientes, e o protocolo AC-TH em 45,8\%. Cerca de 11\% apresentaram toxicidades manejáveis, e 95,8\% completaram o tratamento. Todas as pacientes apresentaram resposta clínica completa ao exame físico e a escolha de tratamento cirúrgico foi de $64,1 \%$ por mastectomia e $35 \%$ por cirurgias conservadoras, com $85 \%$ de esvaziamento axilar e $55 \%$ das pacientes submetidas à reconstrução cirúrgica da mama no mesmo tempo cirúrgico, ocorrendo apenas uma complicação pós-operatória, secundária a infecção. Sete por cento das pacientes recidivaram, majoritariamente à distância, e a taxa de óbito foi de 2,5\%, todos secundários à doença metastática.

Discussão: A prevalência de RPC é mais evidente em tumores classicamente quimiossensíveis, como descrito em literatura, principalmente nas histologias triplo negativa e HER2 isoladamente positivo, com receptores hormonais negativos. Essa prevalência é vista nos resultados apresentados em nosso estudo, quando a minoria das pacientes eram receptor hormonal positivo, diferentemente da distribuição geral de frequência de subtipos histológicos, quando esses tumores são mais prevalentes. A obtenção de RPC após QT-NEO teve associação prognóstica, com menor incidência de recidiva e óbito nessa população que na população total tratada com QT-NEO descrita na literatura, quando as taxas de óbito variam entre 15 a $50 \%$. 